\title{
As Organizações Sociais de Saúde e 0 Desempenho do SUS: Um Estudo sobre a Atenção Básica em São Paulo*
}

\author{
Vera Schattan P. Coelho ${ }^{1}$ \\ Jane Greve ${ }^{2}$
}

${ }^{1}$ Universidade Federal do ABC (UFABC), Santo André, SP, Brasil. E-mail: veraspc@uol.com.br ${ }^{2}$ Danish Institute of Local Governmental Research, Copenhagen, Dinamarca. E-mail: JaGr@kora.dk

\section{INTRODUÇÃO}

$\mathrm{N}$

o Brasil, nos anos 1990 cresceu o debate sobre a possibilidade de ampliar a eficiência e a efetividade da gestão pública a partir de uma distinção mais adequada entre o público e o estatal. Na base deste debate está a ideia de ser necessário distinguir a provisão de serviços públicos (uma clara atribuição do Estado), da produção desses serviços (uma atribuição vinculada não tão evidentemente ao

\footnotetext{
* Este artigo apresenta resultados do projeto "Equidade e Contratualização de Serviços no SUS" financiado com recursos da Fundação de Amparo à Pesquisa do Estado de São Paulo (Fapesp), processos Fapesp 2011 / 20641-5 e Fapesp 2013 / 07616-7. As opiniões, hipóteses e conclusões ou recomendações expressas são de responsabilidade das autora e não necessariamente refletem a visão da Fapesp. Agradecemos pelo trabalho intenso e cuidadoso de pesquisa de Marcelo Dias, Ana Claudia Pedrosa e Vladimir Santana; e a Thiago Greghi, Paula Campos e Marina Barbosa pela sistematização de parte importante do material apresentado neste texto, todos participaram do processo de discussão e análise dos resultados aqui expostos. Agradecemos a Elza Berquó, Argelina Figueiredo, Tania Lago, Maria Luiza Viana, Geraldo Biasoto, Marta Arretche, Adrian Lavalle, Adam Przeworski, Maria Luiza Levi Pahim, Felipe Szabzon, Renata Bichir, Sandra Gomes, Carlos Ranulfo e aos pareceristas anônimos, da Fapesp e da DADOS - Revista de Ciências Sociais, pelos valiosos comentários e sugestões. Agradecemos às Secretarias Municipais de Saúde de São Bernardo do Campo, Mogi das Cruzes, Embu e Suzano que autorizaram a pesquisa e acolheram nossos pesquisadores, e a Fausto MartinoAllan de Souza, Renata Sakashita, Manoel Romero e Vagner Prates pela participação e contribuições ao seminário "A contratação de serviços na atenção básica: Um diálogo entre gestores públicos e pesquisadores".
}

DADOS - Revista de Ciências Sociais, Rio de Janeiro, vol. 59, n-3, 2016, pp. 867 a 901. 
Estado e que pode ser garantida através da contratação tanto direta, quanto indireta de serviços) (Savas, 1987). Para os defensores desta ideia, entidades sem fins lucrativos (Organizações Não Governamentais - ONGs, Organizações Sociais de Saúde - OSSs e Organizações da Sociedade Civil de Interesse Público - OSCIPs) ou mesmo entidades privadas poderiam prestar serviços públicos. Esse movimento reflete tanto tendências internacionais disseminadas pela Nova Administração Pública ${ }^{1}$, quanto a expansão das organizações da sociedade civil a partir da redemocratização do país e da descentralização, como, ainda, as dificuldades encontradas pelos governos na prestação direta de serviços públicos (Mills, 1998; Graef e Salgado, 2009)².

No período também cresceu o debate sobre a necessidade de modernizar a administração do setor público e a contribuição que contratos de gestão poderiam dar tanto para a promoção de maior transparência nas relações entre gestores e prestadores estatais, quanto para ampliar a eficácia na prestação de serviços públicos. Essa agenda estava presente em diversos governos, tendo a França implementado já nos anos 1990 os contratos de gestão com centros de serviços públicos "responsáveis", os quais deveriam formular claramente seus objetivos, além de adotar métodos de avaliação dos resultados (Barbosa, 1996).

No caso do Brasil, há vários modelos de contratação para prestação de serviços públicos sendo praticados simultaneamente. Eles incluem desde a prática de contratos de gestão em hospitais públicos geridos por funcionários públicos; contratos de gestão em hospitais e centros de saúde públicos geridos por OSSs; convênios com OSSs para fornecimento de profissionais de saúde; como, ainda, contratos com autarquias ou fundações públicas ${ }^{3}$. Neste artigo analisamos a experiência brasileira de contratação pelo setor público de OSSs que disponibilizam seja profissionais de saúde para atuarem em Unidades Básicas de Saúde, seja o serviço de gestão dessas unidades, e nomeamos a esse tipo de contratação como "contratação indireta".

Desde os anos 1990, durante a gestão presidencial de Fernando Henrique Cardoso, há registro de municípios que optaram por implementar o Programa Saúde da Família (PSF) via convênio. A partir de 2001, em especial, o município de São Paulo passou a se valer dos convênios para garantir uma política agressiva de expansão do PSF, tendo sido seguido por outros municípios do Estado (Dowbor e Houtzager, 2014; Coelho, Szabzon e Dias, 2014). Nessa mesma década, no estado 
de São Paulo ${ }^{4}$, passou-se a fazer uso dos contratos de gestão com OSSs para inaugurar equipamentos de saúde, tanto de atenção básica (AB), quanto de média e alta complexidade ${ }^{5}$.

No convênio, um órgão da administração pública repassa recursos a uma organização privada não lucrativa, que se compromete a realizar ações que constam do plano de trabalho e, posteriormente, a prestar contas da aplicação de tais recursos ${ }^{6}$. Segundo Di Pietro (2000), o convênio não constitui modalidade de contrato, embora seja um instrumento que o Poder Público utiliza para associar-se a outras instituições. Já os contratos de gestão com OSSs procuram introduzir uma nova lógica na relação entre gestores públicos e prestadores baseada na possibilidade de essas organizações gerenciarem equipamentos e prestarem serviços públicos recebendo financiamento estatal liberado a partir do controle por resultados (MARE, 1997).

Neste artigo procuramos entender como vem se dando a adoção de convênios e contratos de gestão no sistema público de saúde, além de mensurar os impactos dessas decisões sobre a oferta de serviços e a saúde dos usuários do Sistema Único de Saúde (SUS). O artigo está organizado em seis seções incluindo-se esta Introdução. Na próxima seção é feita uma revisão da literatura que orientou a formulação das hipóteses que animaram a pesquisa. Na terceira, apresenta-se a metodologia utilizada. Na quarta seção, são apresentados os resultados das abordagens qualitativa e quantitativa. A primeira abordagem recuperar o contexto político municipal em que se adotou a contratação indireta e, através dela, se discutem as dinâmicas associadas à implementação deste tipo de contratação. A segunda permitiu avaliar o impacto dessas contratações no número de consultas de atendimento primário por usuário do SUS por ano, bem como em diversos indicadores de saúde e de atendimento à saúde. Na quinta seção discutem-se as hipóteses da pesquisa à luz dos resultados apresentados na quarta seção. $\mathrm{Na}$ última são expostas as conclusões do estudo.

\section{O DEBATE}

A contratação indireta suscita ampla controvérsia ideológica, política, econômica e jurídica seja no Brasil, seja internacionalmente. O debate se dá em torno de três grandes eixos. Um deles ressalta as motivações e comportamentos associados ao envolvimento do setor privado na saúde; um segundo eixo discute as condições necessárias para a adequada 
implementação da contratação indireta e, finalmente, um terceiro eixo está centrado no esforço de quantificar possíveis ganhos e perdas associados a esse tipo de contratação.

No primeiro eixo se alinham, de um lado, aqueles que argumentam que a prestação privada de serviços é mais eficiente, transparente e sustentável. Estes, valendo-se em muitos casos dos princípios norteadores da Nova Administração Pública, alegam que faltam incentivos para estimular a eficiência do setor público, o qual tem via de regra objetivos muito amplos e mal definidos, o que ajudaria a explicar seu pobre desempenho. Em contrapartida, tanto a quebra do monopólio do Estado sobre a oferta de serviços públicos quanto o uso de contratos poderiam estimular a competição entre prestadores e a transparência e, com isso, contribuir para ampliar a eficácia e a efetividade na prestação destes serviços. O modelo se assenta basicamente em elementos como flexibilização de regras e introdução de controle por resultados, criação de mecanismos de mercado ou quase-mercado na produção e distribuição de serviços públicos, orientação para o usuário/cliente e estabelecimento de mecanismos de accountability (Mills, 1998).

Já aqueles que se posicionam a favor do setor público argumentam que este promove maior equidade e é mais focado em evidências (Basu et al., 2012). Entre estes estão os sindicatos de servidores públicos e os partidos de esquerda que, com frequência, chamam a atenção para os riscos de contaminação da administração pública pela lógica do lucro, assim como para o fato de que muito foco em incentivos financeiros pode diluir as motivações dos profissionais de saúde associadas a status e altruísmo (López-de-Silanes, Shleifer e Vishny, 1997). Nessa linha, Dijkgraaf, Gradus e Melemberg (2003) apontam que políticos, burocratas e sindicalistas têm grande resistência à contratação indireta, pois enxergam na contratação direta, isto é, de funcionários públicos, um caminho efetivo para garantir o fortalecimento da sua posição institucional dentro do Estado. Já England (2004) aponta para outros riscos associados à adoção da contratação indireta, quais sejam, a possibilidade de inflar custos administrativos e um risco maior de corrupção, tanto em relação à seleção dos fornecedores, quanto à gestão dos contratos.

No Brasil, boa parte deste debate está presente na esfera políticopartidária, tendo o Partido da Social Democracia Brasileira (PSDB) defendido o envolvimento de OSSs na gestão da saúde. Já o Partido 
dos Trabalhadores (PT) e o Partido Democrático Trabalhista (PDT) entraram, em 1998, com uma proposta de Ação Direta de Inconstitucionalidade (Adin no 1.923), contrária à utilização do modelo OS (Organização Social). Dentre os principais pontos, a Adin argumenta que muitos dispositivos constitucionais são violados pelo modelo, tais como: a licitação, a legalidade na gestão de pessoal, o rompimento dos direitos previdenciários dos servidores cedidos, a insubmissão das OSs aos controles interno e externo e o dever do Estado na prestação dos serviços públicos. Em 2003, quando o PT assumiu a Presidência do país, a resistência ao modelo foi ainda mais acirrada e a parceria com as OSs foi amplamente debatida tendo passado por inúmeras críticas, sobretudo, no âmbito das instâncias participativas, como os conselhos e as conferências de saúde, e partidárias (Oliveira, 2016).

O interesse em investigar como esses debates têm influenciado a implementação das políticas municipais de atenção básica nos levou à primeira hipótese do estudo:

H1: Administrações municipais ligadas à coligação capitaneada pelo PSDB adotam a contratação indireta, enquanto administrações ligadas à coligação capitaneada pelo PT evitam esse tipo de contratação.

A segunda vertente do debate enfoca a questão da implementação da contratação indireta. Vários estudos chamam a atenção para um conjunto de precondições necessárias à sua implementação, a saber: a presença de um mercado de fornecedores capaz de garantir a competição entre prestadores, assim como de capacidades estatais necessárias para planejar, definir, monitorar e avaliar o trabalho desses prestadores (Walsh, 1995). Pahim (2009), analisando os primeiros anos da implementação das OSSs paulistas, concluiu que a Secretaria de Estado da Saúde de São Paulo não foi capaz de construir parâmetros para balizar os repasses financeiros às entidades privadas de forma compatível com a noção de gerenciamento por resultados, o que se constitui como a base do contrato de gestão. Tendo em vista investigar as condições de implementação da contratação indireta no estado de São Paulo, formulou-se a segunda hipótese da pesquisa.

H2: A adoção da contratação indireta é facilitada nos municípios onde estão presentes as condições indicadas pela literatura como favoráveis ao seu bom desempenho, i.e., múltiplos fornecedores em condições de competir pelos contratos e capacidades administrativas estatais para gerir esses contratos. 
Quanto à terceira vertente do debate, que busca quantificar ganhos e perdas associados ao uso de contratos e envolvimento do setor privado, seja em termos de eficiência, de eficácia seja de efetividade, há posições bastante variadas na literatura.

Estudos internacionais na área da atenção básica à saúde apontam para alguns resultados positivos associados à contratação indireta de serviços. Loevinsohn e Harding (2004) revisaram 10 experiências de contratação com ONGs em que algum tipo de avaliação sistemática foi feita. Os autores concluíram: "Parece que, em países em desenvolvimento, a contratação de fornecedores que não sejam estatais para fornecer serviços de saúde ou nutrição pode ser eficaz e as melhorias podem ser rápidas"77. Em 2008, Liu, Hotchkiss e Bose publicaram uma revisão de estudos sobre a eficácia da contratação indireta de serviços de atenção básicos em países de renda baixa e média. A revisão traz evidências de que, em muitos casos, a contratação indireta promoveu maior acesso aos serviços de saúde e melhor qualidade.

Witter et al. (2012), em ampla revisão da literatura sobre pagamento por performance, concluíram, no entanto, que as evidências sobre sua contribuição para a ampliação da efetividade na prestação de serviços públicos de saúde em países de renda média e baixa são fracas e insuficientes.

Já Basu et al. (2012), em revisão da literatura que comparou o desempenho do setor privado vis-à-vis o do setor público em países de renda média e baixa, encontraram evidências de que o setor privado tende a violar com mais frequência padrões de comportamento médico e alcança piores resultados em termos da saúde da população atendida, embora preste atendimento mais rápido e atencioso. Segundo os autores, a eficiência tende a ser menor no setor privado, o que resulta em parte dos incentivos que tem para realizar testes e tratamentos desnecessários. Berendes et al. (2011), em revisão sistemática de estudos comparativos sobre a qualidade do atendimento ambulatorial público e privado em países de renda média e baixa, encontraram semelhanças nos resultados reportados para o setor privado lucrativo e não lucrativo, tendo ambos apresentado melhor desempenho que o setor público nos quesitos relativos à oferta de medicamentos e hospitalidade. Segundo os autores, a qualidade dos serviços prestados deixa a desejar tanto no setor público, quanto no privado. 
No Brasil, o desafio de quantificar a contribuição da contratação indireta foi enfrentado pelos autores que analisaram a contribuição dos contratos de gestão à prestação de serviços hospitalares (Mendes Ribeiro e Costa, 2005; Barradas e Mendes, 2006; World Bank, 2006; Ibanez e Vecina Neto, 2007; LaForgia e Couttolenc, 2008; Sano e Abrucio, 2008; Quinhões, 2009; Pahim, 2009; Barbosa e Elias, 2010; Médici, 2011). Essas análises mostraram que a maior flexibilidade operacional das OSSs tende a resultar em um crescimento do volume de serviços prestados. Esses ganhos foram interpretados como associados ao fato de as OSSs não necessitarem realizar concurso público para seus funcionários e tampouco se sujeitarem a planos de carreira para fixar sua remuneração (Sano e Abrucio, 2008; Barbosa e Elias, 2010). O estudo de Médici (2011) aponta para ganhos de eficiência alcançados pelas OSSs ao reduzirem o gasto por procedimento (ampliação das taxas de leitos ocupados e redução do custo dos serviços). Para Médici, esses ganhos estão relacionados ao controle financeiro imposto pela contratualização, que, ao fixar metas e penalizar o seu não cumprimento com redução automática de repasse financeiro, ou mesmo, no limite, com o rompimento da relação contratual, incentiva o bom desempenho dos prestadores. Pouco se sabe, no entanto, sobre o processo e os impactos da adoção destes contratos na atenção básica.

Esse conjunto de estudos traz evidências que apontam para a possibilidade de a contratação indireta estar associada à ampliação da oferta de serviços. As evidências quanto à eficiência e efetividade desse tipo de contratação são contraditórias. Em diálogo com essa literatura, e dado que nosso estudo não tratou de aspectos associados aos custos envolvidos na contratação direta e indireta, formulamos duas hipóteses adicionais para guiar nossa pesquisa, uma delas relativa à oferta de serviços e a outra relativa à efetividade desses serviços:

H3: A adoção de convênios de serviços e contratos de gestão contribuiu para aumentar a oferta de serviços básicos oferecidos pelo SUS.

H4: A contratação de OSSs na atenção básica pode levar a resultados na saúde da população menos favoráveis que aqueles alcançados por serviços que não utilizam este tipo de contratação.

Para analisar o papel das motivações e das condições organizacionais e aferir as quatro hipóteses enunciadas, realizamos, entre 2012 e 2014, um estudo enfocando a experiência da contratação indireta na atenção básica no estado de São Paulo - a experiência brasileira que mais avan- 
çou na parceria com Organizações Sociais de Saúde, tanto no nível estadual, quanto no âmbito municipal (Graef e Salgado, 2012). A metodologia utilizada na pesquisa é apresentada na próxima seção.

\section{A PESQUISA}

Nos anos 1990, a gestão da atenção básica passou a ser responsabilidade do município e há os primeiros registros de municípios que optaram por implementar o Programa Saúde da Família via convênio (DAB, 2002). Como se pôde ver na seção anterior, a experiência brasileira de adoção da contratação indireta vem se desenvolvendo desde então, em um cenário de polarização política, pouca clareza sobre as condições em que vem sendo implementada e incerteza quanto a seus impactos.

Para avançar na compreensão destas questões, que dialogam diretamente com as hipóteses apresentadas anteriormente, realizamos dois estudos, um de caráter qualitativo e outro quantitativo. A primeira hipótese, que busca identificar "quem" contrata indiretamente, foi discutida com base nos resultados dos dois estudos. A segunda, que trata de aspectos ligados à implementação da contratação indireta foi discutida a partir do material colhido na pesquisa qualitativa. Finalmente, as hipóteses terceira e quarta foram discutidas com base nos dados e análises disponibilizados pelo estudo quantitativo.

\section{O Estudo Qualitativo}

A etapa qualitativa da pesquisa começou em 2013, ano em que os prefeitos eleitos em 2012 assumiram a gestão municipal, e se estendeu até novembro de 2014. Para definir os municípios onde esta etapa seria realizada, selecionamos dentre os 27 municípios de porte médio do Estado (aqueles com população entre $250 \mathrm{mil}$ e $800 \mathrm{mil}$ habitantes), quatro entre os que apresentam alta proporção de contratação indireta, isto é, onde $10 \%$ ou mais dos profissionais da atenção básica $(\mathrm{AB})$ eram contratados por $\mathrm{OSSs}^{8}$. Pesou na escolha dos municípios a boa vontade dos gestores em autorizarem o estudo. Na Tabela 1 apresentamos os municípios selecionados e as variáveis que foram levadas em conta na seleção.

O histórico e a dinâmica da contratação indireta em cada um dos quatro municípios foram levantados através de pesquisa documental, visitas a campo e 103 entrevistas semiestruturadas com os atores-chave 
Tabela 1

Informações sobre os Quatro Municípios de Porte Médio Selecionados (2012)

\begin{tabular}{|c|c|c|c|c|}
\hline & $\begin{array}{c}\text { Embu das } \\
\text { Artes }\end{array}$ & Suzano & $\begin{array}{c}\text { Mogi das } \\
\text { Cruzes }\end{array}$ & $\begin{array}{c}\text { São Bernardo } \\
\text { do Campo }\end{array}$ \\
\hline IDSUS* & 3 & 3 & 2 & 2 \\
\hline População & 246.251 & 267.953 & 396.499 & 775.428 \\
\hline \% População SUS ${ }^{9}$ & 63,4 & 59,1 & 51,2 & 47,4 \\
\hline \% Contratação Indireta na $\mathrm{AB}$ & 22,6 & 60 & 54 & 77 \\
\hline
\end{tabular}

Fonte: IDSUS; CNES; Pesquisa Equidade e Contratualização de serviços no SUS. Elaboração: Cebrap/NSCD.

* O IDSUS (Indicador SUS) é construído levando-se em consideração três conjuntos de indicadores municipais (condições de desenvolvimento socioeconômico; nível de saúde da população e condições infraestruturais de atenção à saúde, sobretudo na média e alta complexidade). O indicador varia de 1 a 6 , valores menores indicam melhores condiç̃̃es.

dos governos municipais, OSSs parceiras, funcionários das unidades básicas e conselheiros de saúde. Para permitir a comparação sistemática das variáveis de interesse, organizamos as informações coletadas em quatro eixos de análise: capacidade administrativa; controle social; caracterização da OSS; e ciclo de planejamento, monitoramento e avaliação. A análise das entrevistas por esses quatro eixos permitiu ampliar o conhecimento sobre a implementação e os impactos da contratação indireta nos serviços da atenção básica, além de possibilitar a identificação de inovações que estão ocorrendo na gestão da atenção básica.

Adicionalmente, analisamos um conjunto de indicadores com o intuito de conhecer a trajetória dos sistemas de saúde destes municípios no período 2008-2012. Buscávamos identificar condições prévias que pudessem ter influenciado as decisões referentes à contratação indireta que foram tomadas pelos gestores que assumiram a saúde em $2013^{10}$. Os resultados desta etapa da pesquisa são apresentados na quarta seção.

\section{Pesquisa Quantitativa}

A pesquisa quantitativa foi conduzida de modo a permitir uma avaliação do impacto da contratação indireta na atenção básica nos 645 municípios do estado de São Paulo.

Em revisão de literatura sobre o impacto da atenção básica, Shi (2012) aponta que, a partir de 12 meses de tratamento com modelos centrados na atenção básica como, por exemplo, o PSF, podem se verificar resul- 
tados positivos e consistentes nos indicadores de saúde da população tratada. A literatura relata também uma relação significativa e negativa entre o número de consultas de saúde primária e a mortalidade infantil e doenças respiratórias (Caldeira et al., 2005; Macinko et al., 2007), indicando que esses fatores são importantes para avaliar o impacto de reformas adotadas na atenção básica. Finalmente, mantendo-se tudo o mais constante (ceteris paribus), é razoável esperar que um sistema de saúde básico mais efetivo contribua para a redução no número de internações por doenças que poderiam ser prevenidas e tratadas por serviços de atenção básica.

Para realizar essa avaliação, coletamos dados de diversas fontes e utilizamos o método da diferença-em-diferenças (vide Angrist e Pischke, 2009; Imbens e Wooldridge, 2009). A descrição detalhada da estratégia empírica desenvolvida no estudo está descrita no Anexo 2 on line $e^{11}$.

A Tabela 1 do Anexo 1 on line descreve as fontes dos dados que incluímos em nossos modelos econométricos. O período coberto em nossa análise foi definido em função da disponibilidade de dados. Para o número de consultas de atendimento básico e taxas de mortalidade e internação, há informações de 2001 a 2012. Todas as variáveis de controle estão disponíveis de 2001 a 2012 exceto renda per capita, que existe apenas em 2002 e 2010.

Os dados sobre a implementação de convênios e contratos de gestão com OSSs nos municípios foram coletados do Cadastro Nacional de Estabelecimentos de Saúde (CNES) e estavam disponíveis de 2009 a 2012. A qualidade dos dados para os primeiros anos da série era bastante precária tendo melhorado sensivelmente a partir de 2011, por isso foi utilizado um indicador de tratamento do ano de 2011 e uma medida de resultado de $2012^{12}$. Para identificar se um município estava ou não utilizando essa estratégia, calculamos a porcentagem de profissionais de saúde na atenção básica empregados através de contratos externos. Em 2012, 223 municípios tinham um ou mais empregados em contratos externos na atenção básica ${ }^{13}$. Os dados apresentados no CNES não permitem distinguir a contratação via convênios das contratações via contrato de gestão, o que nos levou a tratá-los na análise como uma única categoria: os profissionais contratados por OSSs. Esse fato representou um limite importante, pois não nos permitiu explorar o impacto de diferentes tipos de contrato sobre as variáveis dependentes. 
Como não se esperava que municípios com pouquíssimos funcionários em contratos externos tivessem seus resultados afetados por esse tipo de contrato, classificamos como "tratados" (isto é, municípios que utilizam contratos externos na atenção básica) os municípios com mais de $10 \%$ dos profissionais de saúde da atenção básica em contratos externos ${ }^{14}$.

Como mencionado, o CNES não coletava informações sobre vínculos indiretos para os anos anteriores a 2009. Trabalhamos assim com a suposição de que a difusão da contratação indireta começa de fato a ganhar força a partir das gestões municipais que se iniciaram em 2005 e que nenhum dos municípios foi afetado pelo tratamento no ano de 2004. Todos os modelos escolhendo pré-observações de 2002 foram estimados e os resultados foram praticamente os mesmos quando se escolheu 2002 ou 2004 como ano anterior ao início da contratação in$\operatorname{direta}^{15}$. A decisão de trabalhar com 2005 se baseou na ampliação do uso de convênios a partir de 2001 e de contratos de gestão a partir de 2005 pela Secretaria Municipal de Saúde de São Paulo (Dowbor e Houtzager, 2014; Coelho, Szabzon e Dias, 2014) e na difusão desses modelos para outros municípios, como mostrado pelo nosso estudo qualitativo e apresentado na próxima seção deste artigo.

A abordagem aqui utilizada na avaliação da contratação de serviços de saúde é inovadora em vários sentidos. Primeiro, foram coletadas informações sobre convênios e contratos de gestão de diversas fontes, tendo essas informações sido comparadas com os resultados obtidos em um estudo qualitativo sobre esses contratos em diversos municípios do estado de São Paulo (Coelho et al., 2014). Assim, a variável utilizada para medir se um município contratou ou não serviços de atenção primária foi validada, o que permitiu ampliar a confiança nos resultados do estudo. Segundo, comparando-se com a literatura internacional existente sobre o impacto da contratação de serviços de saúde, utilizamos dados de painéis com informações anuais de 2001 a 2012. Isto permite mostrar as tendências na saúde e na oferta de serviços para períodos anteriores à adoção dos contratos - tanto para municípios que adotaram esse tipo de contrato, quanto para os municípios-controle - e, assim, testar a hipótese de tendência comum, o que permite validar a estratégia da diferença-em-diferenças ${ }^{16}$. Na próxima seção são apresentados os resultados destes estudos. 


\section{RESULTADOS}

\section{Quem Contrata as OSSs? Por quê?}

A contratação indireta começa a ser adotada pelas autoridades sanitárias dos municípios incluídos no estudo qualitativo, como se pode ver na Tabela 3, a partir das gestões municipais que assumiram em 2001, seguindo um movimento de expansão da atenção básica que ganhou força no município de São Paulo durante a gestão de Marta Suplicy, do PT (Dowbor e Houtzager, 2014). A adoção dos contratos de gestão a partir de 2009 também segue um movimento que ganhou força na cidade de São Paulo a partir de 2005, durante a gestão de José Serra, do PSDB, com a contratação de OSSs para gerir as unidades de Assistência Médica Ambulatorial (AMAs), e as Unidades Básicas de Saúde (UBSs) (Coelho, Szabzon e Dias, 2014).

Para examinar os fatores que pesam na decisão de contratar e a questão da endogeneidade, isto é, se a adoção da estratégia de contratação depende de características específicas dos municípios, foram estimados os determinantes da implementação da estratégia de contratação utilizando um modelo probit simples. Nesse modelo incluímos variáveis defasadas - i.e., dados de 2010 - e variáveis que medem mudanças de 2007 a 2010.

Os resultados que podem ser vistos na Tabela 2 indicam que os municípios com menos de 10 mil habitantes e com alta porcentagem de usuários do SUS têm menor probabilidade de implementar a estratégia de contratação ${ }^{17}$. Nenhum dos outros coeficientes, com exceção daqueles associados à raça, está próximo de ser significativo.

Quanto à questão da endogeneidade dinâmica, os resultados mostram que nem o estado de saúde anterior, nem as mudanças nas variáveis de saúde e no uso de serviços de saúde são significativamente diferentes de zero ${ }^{18}$. Além disso, a renda per capita, o número de equipes do PSF e o partido político do prefeito não estão correlacionados significativamente com a probabilidade de contratação em nenhum dos modelos.

A Tabela 3 introduz os resultados do estudo qualitativo realizado em quatro municípios médios do estado de São Paulo. Nela podem-se ver os partidos que estiveram à frente das gestões municipais a partir de 2001 e o tipo de contrato por elas adotado. 
As Organizações Sociais de Saúde e o Desempenho do SUS

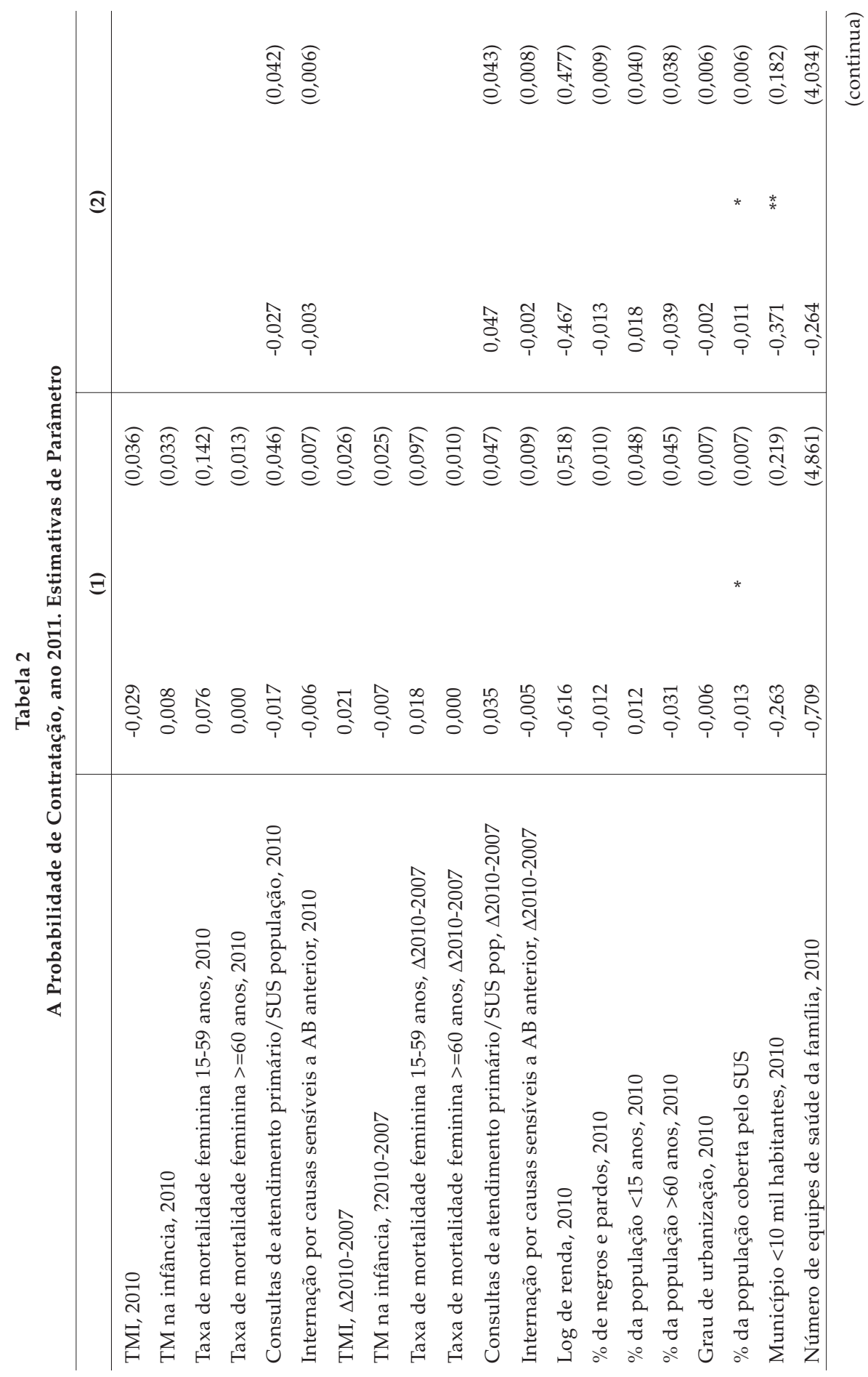

DADOS - Revista de Ciências Sociais, Rio de Janeiro, vol. 59, nº 3, 2016 


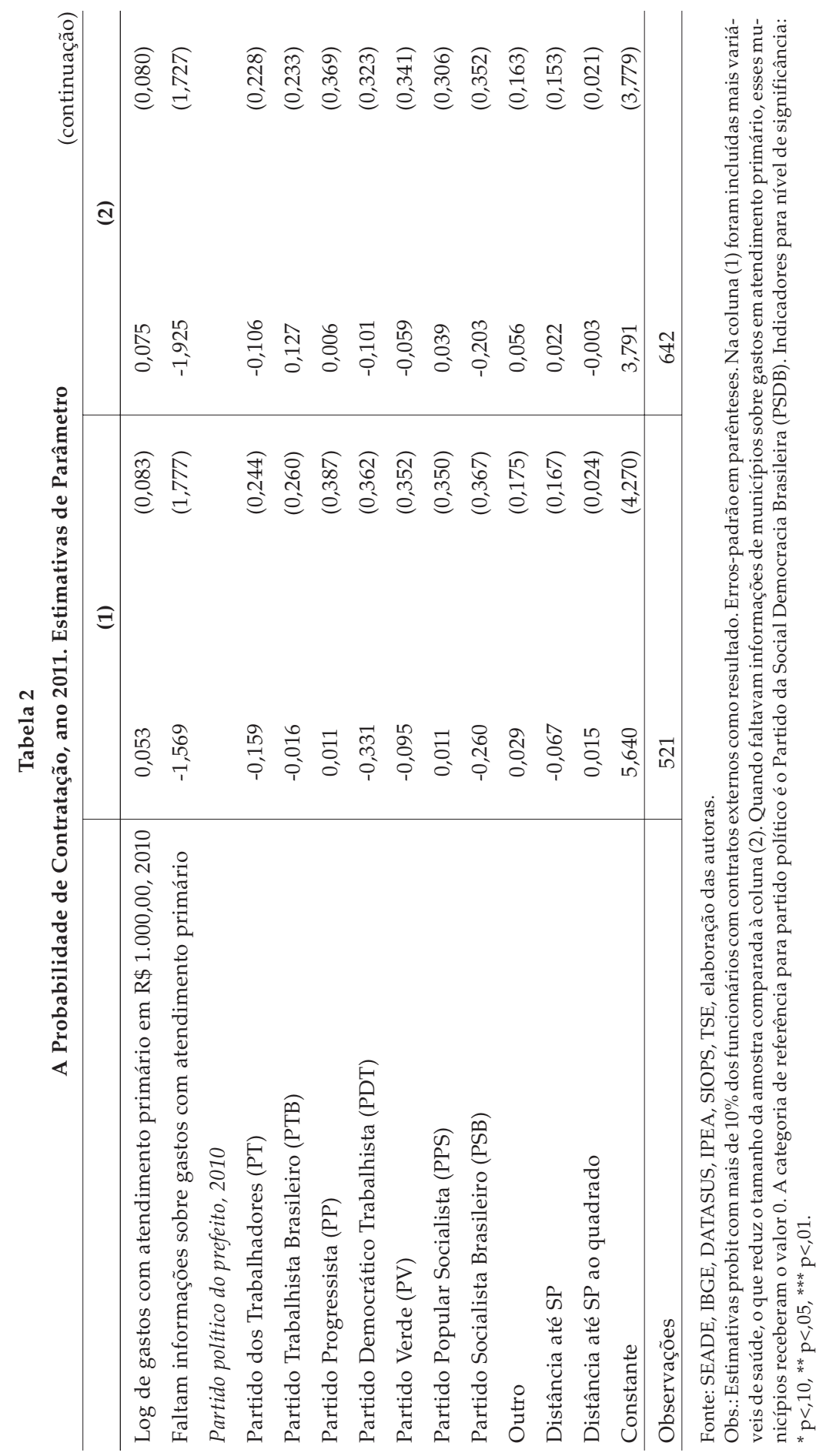


Tabela 3

Partido no Poder e Tipo de Contrato, 4 Municípios Selecionados, 2001- 2015, Estado de São Paulo

\begin{tabular}{|c|c|c|c|c|}
\hline Mandato & $\begin{array}{c}\text { Embu das } \\
\text { Artes }\end{array}$ & Suzano & $\begin{array}{l}\text { Mogi das } \\
\text { Cruzes }\end{array}$ & $\begin{array}{c}\text { São Bernardo } \\
\text { do Campo }\end{array}$ \\
\hline $2013-2015$ & PT $\uparrow$ & PSDB $\uparrow$ & PSD & PT $\uparrow$ \\
\hline 2009-2012 & PT $\uparrow$ & PT & DEM & PT $\uparrow$ \\
\hline $2005-2008$ & PT $\uparrow$ & PT & PSDB $\uparrow$ & PSB $\uparrow$ \\
\hline 2001-2004 & PT $\uparrow$ & PFL & PSDB $\uparrow$ & PPS \\
\hline $\begin{array}{l}\text { Tipo de contrato } \\
\text { indireto }\end{array}$ & Convênio & $\begin{array}{c}\text { Convênio e } \\
\text { Contrato de } \\
\text { gestão }\end{array}$ & $\begin{array}{c}\text { Convênio e } \\
\text { Contrato de } \\
\text { gestão }\end{array}$ & Convênio \\
\hline
\end{tabular}

Fonte: Elaboração própria com base nos resultados da análise qualitativa.

Obs.: Convênio ^; Contrato de Gestão

A Tabela 3 mostra quando os municípios começaram a assinar convênios com OSSs. Indica também que a contratação indireta é praticada por administrações municipais lideradas tanto por partidos de esquerda, quanto de direita (PT, PSD, PSB, PSDB, DEM/PFL) ${ }^{19}$.

Esses resultados, tanto do estudo quantitativo, quanto do qualitativo, mostram que, apesar do debate político sugerir que os partidos de esquerda evitam a contratação indireta, não é isso o que vem acontecendo na gestão municipal da atenção básica no estado de São Paulo. Para explicar esse achado inesperado contamos com os depoimentos dos gestores que apontaram unanimemente para o fato de que a decisão de adotar a contratação indireta foi motivada pelos constrangimentos impostos pela Lei de Responsabilidade Fiscal. Esta lei, promulgada em maio de 2000, regulamenta a parte referente à Tributação e Orçamento da Constituição Federal, tendo estabelecido as normas gerais de finanças públicas a serem observadas pelos três níveis de governo: Federal, Estadual e Municipal. No caso dos municípios, definiu-se que os gastos com pessoal, ativo e inativo, não podem ultrapassar $60 \%$ da sua receita corrente líquida.

Ora, uma vez adotada a contratação indireta, como expediente para contornar os limites impostos à contratação de pessoal, há indicações de que seu uso foi reforçado em função dos ganhos que os gestores e políticos passaram a perceber em termos da flexibilidade para contratar e agilidade para gerir os recursos humanos. Segundo os entrevista- 
dos, a adoção de contratos indiretos permite maior flexibilidade na contratação de pessoal, o que facilita a contratação de novos profissionais, seja quando unidades de saúde estão sendo abertas ou ampliadas, seja quando o rendimento dos profissionais não é satisfatório, seja, ainda, quando há alta rotatividade desses profissionais. Um impedimento, indicado pelos gestores, à adoção da contratação indireta é a resistência dos sindicatos de funcionários públicos e a pressão que exercem junto aos conselhos e ao governo.

\section{A Implementação da Contratação Indireta na Gestão Municipal de Atenção Básica}

Para acompanhar o processo de implementação da contratação indireta levado a cabo pelos gestores municipais que assumiram as Secretarias de Saúde em 2013, fizemos um levantamento das condições preexistentes no sistema de saúde, bem como das iniciativas que realizaram após assumirem. Os resultados desse levantamento são apresentados a seguir.

Ampliando, homogeneizando a rede e contratando OSSs: Até 2012, entre os municípios pesquisados no estudo qualitativo, distribuíam-se UBSs tradicionais, que contavam com médicos especialistas; Unidades Básicas de Saúde da Família (UBSF) ${ }^{20}$, que contavam com médicos generalistas e UBSs mistas que agregavam os dois modelos. Essa situação representa um fator de confusão tanto para os gestores da Secretaria Municipal de Saúde (SMS) e das unidades de saúde, quanto para a população usuária, uma vez que, mesmo sendo todas elas unidades de atenção básica, contavam com gerentes contratados sob diferentes regimes de trabalho, ofereciam diferentes serviços e seguiam diferentes regras de uso.

Para enfrentar esta situação, Mogi das Cruzes promoveu uma clara diferenciação entre duas redes. Uma formada pelas UBSs tradicionais, com servidores públicos perfazendo $100 \%$ dos cargos, e outra de UBSFs, onde todos os funcionários são contratados e respondem à OSS Centro de Estudos e Pesquisas Dr. João Amorim (Cejam). Desde o início da parceria com o Cejam, em 2010, o número de UBSF passou de 7 para 11 sendo estas novas UBSFs localizadas em áreas mais periféricas da cidade.

São Bernardo do Campo investiu pesadamente na saúde nos últimos anos, e vem homogeneizando sua rede. Todas as unidades básicas fo- 
ram reformadas recentemente e transformadas em unidades de estratégia de saúde expandida, o que significa que suas equipes são integradas por generalistas e especialistas agregando-se, assim, médicos estatuários às equipes de ESF. Essas unidades foram regionalizadas e cada conjunto de quatro ou cinco unidades está referenciada a uma Unidade de Pronto Atendimento (UPA). Essa reorganização assim como o expressivo crescimento da atenção básica no município foram facilitados pela contratação de serviços através da Fundação $A B C$. Hoje mais da metade dos funcionários da atenção básica são vinculados a ela.

Para os municípios de Embu e Suzano, o uso da contratação indireta facilitou a expansão do PSF nas áreas periféricas das cidades, porém não foi utilizado para promover a homogeneização da rede.

Um aspecto que facilitou o recurso às OSSs entre os municípios pesquisados foi a presença na região metropolitana de várias dessas entidades com experiência na gestão básica. Quanto à forma de contratá-las, em Mogi das Cruzes houve concorrência e, segundo foi informado aos pesquisadores, "diferentes OSSs participaram". Mais recentemente em Suzano houve chamamento público para seleção de nova parceira via contrato de gestão.

Esses caminhos mostram bem como os gestores municipais puderam usar a contratação indireta para facilitar a implementação de diferentes estratégias destinadas a enfrentar os problemas postos pela heterogeneidade da rede de serviços. Mostra também que todos eles puderam se valer da contratação indireta para promover a expansão da Estratégia de Saúde da Família nas áreas periféricas dessas cidades.

Ampliar a oferta de serviços e melhorar os indicadores de saúde: Um desafio importante posto aos gestores que assumiram em 2013 era ampliar a oferta de serviços básicos de saúde e sua efetividade. Entre os quatro municípios estudados apenas um (1) oferecia um número de consultas compatível com o parâmetro, de 2 a 3 consultas básicas por ano, recomendado pelo Ministério da Saúde. No caso da porcentagem de nascidos vivos com sete ou mais consultas de pré-natal e da taxa de mortalidade infantil, apenas dois municípios conseguiram alcançar as metas, respectivamente de $90 \%$ e taxas inferiores a 10 por 1.000 nascidos vivos, recomendadas pelo Ministério da Saúde ${ }^{21}$. Para lidar com estes desafios foram definidas diferentes estratégias. 
Uma estratégia que apareceu em todos os municípios estudados foi o investimento no aperfeiçoamento dos sistemas de informação, planejamento e avaliação. Em todos os municípios foi implantado o Sistema de Informação da Atenção Básica (SIAB) em todas as unidades básicas de saúde. Nesses municípios há uma cultura de monitoramento, os procedimentos são registrados sistematicamente e informados à SMS que costuma reagir quando identifica que a produção das unidades não está sendo satisfatória. Ainda assim foram encontradas poucas evidências de que esses sistemas estejam contribuindo para criar uma cultura de avaliação das unidades e programas. Nesse sentido, a experiência presente em todos os municípios de participar do Programa Nacional de Melhoria do Acesso e da Qualidade da Atenção Básica (PMAQ) promovido pelo Ministério da Saúde, assim como o contrato de gestão firmado entre a OSS Cejam e a SMS em Mogi das Cruzes, abriram uma nova via nesse cenário, através da qual o monitoramento é associado à avaliação, ao planejamento de metas futuras e a incentivos. Essas são, no entanto, práticas pontuais que ainda não estão estabelecidas como rotinas.

Outra estratégia importante tem sido a contratação de novos profissionais para atuarem na atenção básica. Em Embu e, sobretudo, em São Bernardo contrataram-se muitos profissionais através de contratos indiretos, porém buscou-se manter a gerência das unidades sob responsabilidade de funcionários públicos. Já em Suzano, a SMS indicou para ocupar a gerência da grande maioria das unidades profissionais em contratos externos, esperando com isso ampliar sua influência sobre a gestão destes equipamentos. Em Mogi das Cruzes, nas unidades tradicionais, a SMS apostou no rodízio de funcionários como forma de ter maior influência sobre elas, enquanto nas UBSFs, o Cejam preferiu fixar os profissionais nas unidades.

Para melhorar a implementação dos programas de saúde ${ }^{22}$, Embu e São Bernardo do Campo investiram na consolidação de uma agenda quinzenal de reuniões entre os gestores da Secretaria e das unidades. Nessas reuniões se discutem os problemas enfrentados nas unidades e se dá a troca de experiências sobre como solucioná-los. Ao lado da ênfase nas reuniões e na comunicação, há também a preocupação em manter ativos os conselhos de saúde. Há um discurso reiterado por gestores e gerentes que encoraja o trabalho de equipe e não a competição, bem como a construção compartilhada de uma visão sobre os objetivos do sistema. Nessa linha, São Bernardo monitora a produção das 
unidades e criou em 2014 uma área de análise estratégica para analisar essas informações e, com isso, subsidiar o planejamento da SMS e das unidades, sem, no entanto, fazer uso dessa informação para premiar ou punir as unidades e seus profissionais. Evita-se mesmo publicizar esses dados ressaltando-se que a relação entre a SMS e as unidades não deve ser mediada pela definição de metas e de avaliações.

Já em Mogi das Cruzes e Suzano, os gestores decidiram implantar contratos de gestão e, com isso, incentivar a cultura da avaliação que, segundo eles, deve contribuir para a boa performance dos prestadores, a transparência do sistema e a melhoria da própria gestão. Esses municípios têm investido na definição de um processo mais transparente de escolha da OS (com abertura de edital e concorrência) e se confrontado com as dificuldades de definição das metas de produção do contrato de gestão e de estabelecer indicadores que permitam avaliar o desempenho da OSS, bem como com a criação de uma agenda de reuniões para acompanhar o andamento do trabalho feito pela OSS contratada. No caso de Mogi das Cruzes, a gestão e a comunicação com as unidades implementadoras da ESF e seus profissionais fica a cargo da OSS Cejam, que realiza um trabalho regular no sentido de aproximar os supervisores e as equipes da unidade e criar uma visão compartilhada dos problemas e das soluções que vão sendo geradas pelas unidades. Nesses municípios, pouca atenção é dada aos conselhos locais de saúde.

Em suma, os quatro secretários de saúde que assumiram a gestão da Secretaria Municipal de Saúde em 2013 encontraram condições bastante diversas. Algumas delas, como, por exemplo, uma rede de serviços mais homogênea em São Bernardo do Campo, favorece o bom desempenho da contratação indireta, e outras que aparecem nos quatro municípios eram desfavoráveis como, por exemplo, a falta de sistemas de avaliação. Em todos os casos ficou claro, no entanto, o compromisso da gestão municipal com a melhoria da atenção básica, bem como o fato de esta ser reconhecida pelos gestores como um fator que contribuiu para o desempenho eleitoral.

O quadro relatado acima está longe de poder ser reconhecido como preenchendo as condições descritas no modelo ideal formatado pela Nova Administração Pública. Uma imagem mais aderente à realidade encontrada é a de gestores públicos que, pressionados pela Lei de Responsabilidade Fiscal, recorreram à contratação indireta para viabilizar 
a adequada gestão e expansão da atenção básica. As opções feitas por estes municípios mostram bem, no entanto, como a contratação indireta vem sendo apropriada de diferentes formas pelos gestores municipais. Uma mais participativa e cooperativa, outra mais contratualista e focada em incentivos. Embu e São Bernardo do Campo ressaltam que o convênio permite flexibilizar o processo de contratação de profissionais, enquanto a gestão de todo o sistema fica a cargo da Secretaria de Saúde. Nesses municípios o convênio é visto sobretudo como um instrumento que viabiliza a contratação de pessoal. Já Suzano e Mogi das Cruzes valorizaram o uso da contratação indireta enquanto instrumento para promover a contratualização das relações entre gestores e profissionais da saúde. Nesses casos a autonomia gerencial e o controle por resultados, fatores que diferenciam o convênio e do contrato de gestão, são valorizados.

\section{AVALIANDO OS IMPACTOS DE ADOTAR A ESTRATÉGIA DE CONTRATAÇÃO INDIRETA}

Nesta seção apresentamos os resultados da avaliação de impacto dos programas de contratação indireta de serviços de atenção básica no estado de São Paulo. Estes resultados são apresentados na Tabela 4.

A estratégia de contratação indireta alcançou um impacto grande e significativo no que diz respeito à oferta de consultas básicas. As estimativas por parâmetro mostram que o número de consultas de atendimento primário por usuário do SUS aumenta em aproximadamente uma consulta ao ano quando controlamos as condições iniciais em diferentes municípios. Assim, a implementação de uma estratégia de contratação indireta aponta para o aumento da oferta de consultas básicas ${ }^{23}$. Está menos clara, no entanto, a contribuição dessa ampliação da oferta para uma melhora no estado de saúde da população. Os resultados para mortalidade infantil e na infância e a internação de crianças estão em logs, sendo possível interpretá-los como mudanças na porcentagem desses índices.

As estimativas por parâmetro sugerem que a contratação indireta reduz a internação por causas sensíveis à atenção básica ${ }^{24}$. Também indicam que a contratação indireta reduz a mortalidade infantil e na infância, assim como a internação por infecções respiratórias agudas, mas nestes casos não podemos descartar que essas estimativas por parâmetro sejam zero. 


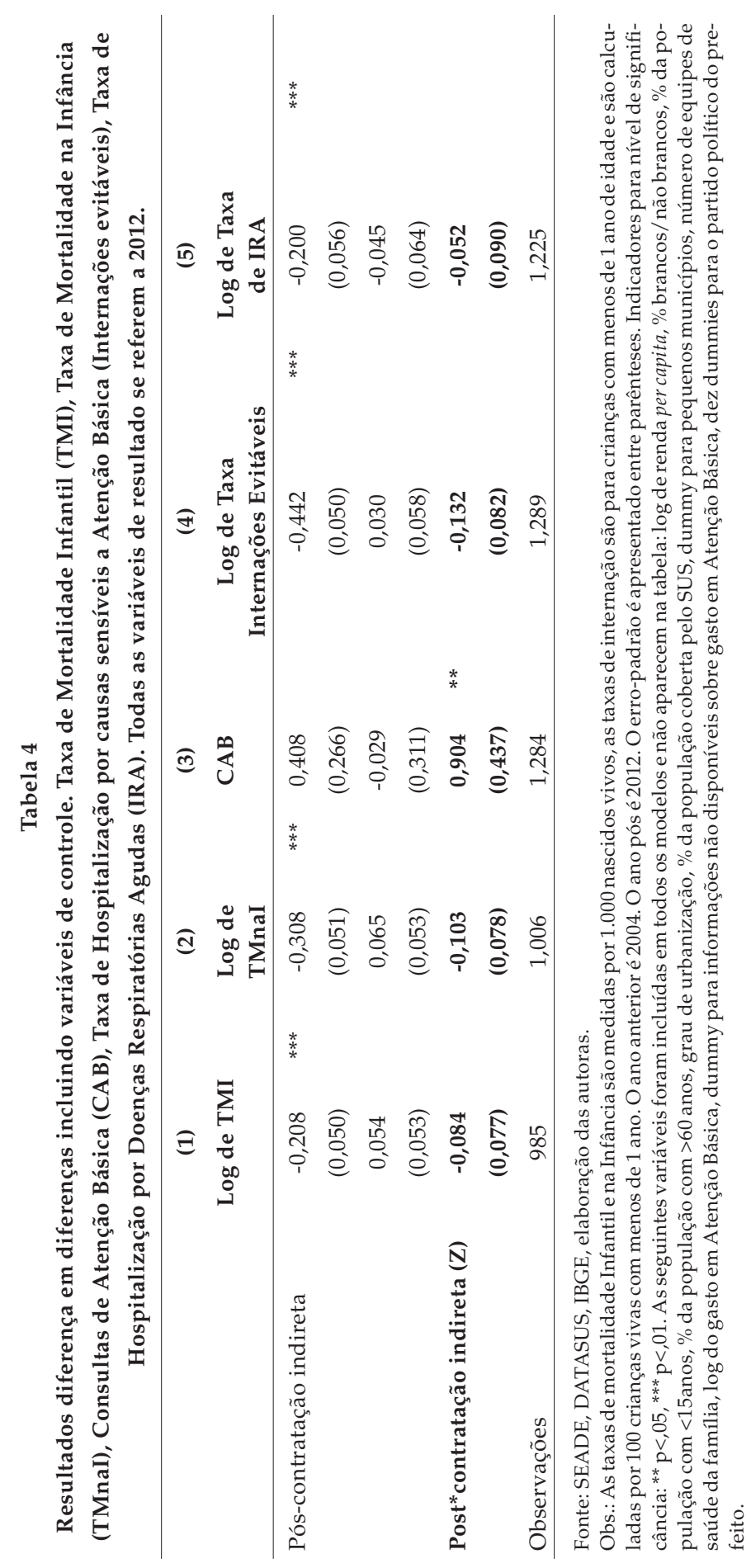

DADOS - Revista de Ciências Sociais, Rio de Janeiro, vol. 59, n 3, 2016 
Vários exercícios foram feitos para testar a robustez do modelo. Esses testes são apresentados no Anexo 3 on-line ${ }^{25}$. Primeiro, controlamos os efeitos fixos para os municípios e suas condições iniciais. Segundo, testamos a linha de corte que utilizamos para definir os municípios que deveriam ser incluídos no grupo de tratamento (porcentagem de profissionais de saúde contratados indiretamente). Terceiro, incluímos uma variável contínua medindo a porcentagem de profissionais de saúde em contratos externos. Quarto, deixamos fora da análise municípios com menos de 5 mil habitantes. Quinto, excluímos o município de São Paulo. Finalmente, testamos todos os modelos usando pré-observações de 2002 em vez de 2004. Os resultados para todos esses testes de robustez são essencialmente os mesmos daqueles mostrados na Tabela $5^{26}$.

Finalmente, cabe comentar que podemos estar superestimando o efeito da contratação indireta, pois eles representam o efeito médio nos municípios tratados, os quais se autosselecionaram para a adoção da contratação indireta. Assim, implementar a contratação em todo o estado de São Paulo pode não ser igualmente benéfico para todos os municípios, assim como pode não ter efeito nos serviços de saúde daqueles municípios que não necessitam mudar sua organização, ou não contam com a capacidade de se beneficiar do aumento de flexibilidade oferecido pela contratação.

\section{DISCUSSÃO}

Discutimos aqui os resultados apresentados na seção anterior à luz das hipóteses expostas no início do artigo.

A primeira hipótese que orientou o estudo indica que administrações municipais ligadas à coligação capitaneada pelo PSDB adotarão a contratação indireta, enquanto administrações ligadas à coligação capitaneada pelo PT evitarão esse tipo de contratação.

Os resultados apresentados na seção Quem Contrata as OSSs? Por quê? sugerem que esta hipótese deve ser descartada. Os resultados do estudo quantitativo mostram que o partido político do prefeito não está correlacionado significativamente com a probabilidade de contratação em nenhum dos modelos. Os resultados do estudo qualitativo reforçam esse achado mostrando que a contratação indireta é praticada por administrações municipais lideradas tanto por partidos de esquerda, quanto de centro e de direita (PT, PSD, PSB, PSDB, PFL/DEM). O relato dos gestores entrevistados sugere que este alinhamento, em tor- 
no da contratação indireta por parte de municípios governados por partidos de diferentes orientações ideológicas, foi induzido por um constrangimento legal, a Lei de Responsabilidade Fiscal.

O estudo qualitativo sugere, no entanto, que, se inicialmente políticos e gestores municipais pressionados pelos constrangimentos impostos à contratação de servidores públicos pela Lei de Responsabilidade Fiscal adotaram os convênios, nos anos subsequentes se delineou uma clivagem partidária na forma de implementar a contratação indireta. Essa clivagem se deu à medida que os municípios governados pelo PT e partidos da coligação adotaram um estilo mais participativo, e aqueles governados pelo PSDB e coligados um estilo mais contratualista.

A discussão destes resultados com gestores e pesquisadores permitiu iluminar o papel da experiência do município de São Paulo na disseminação destas práticas para os demais municípios do Estado. Neste município os convênios foram adotados, sobretudo a partir de 2001, na gestão de Marta Suplicy, do PT. Já os contratos de gestão foram adotados a partir de 2005, na gestão de José Serra, do PSDB.

Finalmente, em relação à pergunta "quem contrata indiretamente", os resultados da pesquisa quantitativa mostram que os municípios com menos de 10 mil habitantes com alta porcentagem de usuários do SUS têm menor probabilidade de implementar a estratégia de contratação indireta.

A segunda hipótese apresentada indica que a adoção da contratação indireta é facilitada nos municípios onde estão presentes as condições indicadas pela literatura como favoráveis ao seu bom desempenho, i.e., múltiplos fornecedores em condições de competir pelos contratos e capacidades administrativas estatais para gerir esses contratos.

Os resultados do estudo qualitativo apresentados na seção A implementação da contratação indireta na gestão municipal de atenção básica sugerem que, para os casos estudados, esta hipótese deve ser descartada. Eles mostram não só que a adoção da contratação indireta se deu de forma independente dessas condições como, também, que elas estavam pouco presentes em 2013, quando os gestores responsáveis pelas iniciativas relatadas neste estudo assumiram seus postos na Secretaria Municipal de Saúde.

Ao acompanharmos essas iniciativas fica claro, no entanto, que esses municípios vêm fazendo avanços no sentido de estabelecer essas con- 
dições. Alguns praticam o chamamento público para selecionar a OSS; outros têm investido no controle social e no aperfeiçoamento dos seus sistemas de informática; o SIAB está sendo progressivamente implantado em todas as unidades PSF; há experiências no sentido de homogeneizar a rede de serviços e há empenho em criar dinâmicas que favoreçam a integração e coordenação entre as equipes das unidades de saúde e das secretarias municipais.

Esses avanços pontuais, que estão distribuídos desigualmente pelos municípios, estão longe, no entanto, de configurar um quadro que possa ser reconhecido como preenchendo as condições descritas no modelo ideal formatado pela Nova Administração Pública. Antes, uma perspectiva mais adequada parece reconhecer que dois estilos híbridos de gestão, mais pautados pelas preferências ideológicas dos gestores, do que pelas características organizacionais dos sistemas de saúde, estão sendo amalgamados.

Em São Bernardo do Campo e Embu das Artes a contribuição da contratação indireta à ampliação da oferta de serviços é avaliada como sendo a de flexibilizar a contratação de recursos humanos. O aprimoramento da gestão desses recursos é visto como atrelado ao sucesso de um "estilo participativo" que está, a nosso ver, alinhado a uma tradição dos estudos de desenvolvimento que valoriza os processos de aprendizagem (Locke e Latham, 2006; Patton, 2010), bem como de acordo com autores que criticam processos estritos de monitoramento e avaliação que podem acabar desencorajando processos de adaptação e inovação (Chambers, 2010; Eyben, 2010).

Já em Mogi das Cruzes e Suzano a contribuição da contratação indireta à ampliação da oferta de serviços é avaliada como sendo a de promover um "estilo contratualista", tal como enunciado pela nova administração pública, a qual valoriza a cultura da avaliação, dos incentivos e da competição (Walsh, 1995).

Ou seja, políticos e gestores vêm buscando aprimorar as condições organizacionais a partir de diferentes enfoques, os quais têm levado a diferentes formas de lidar com a contratação indireta. Assim em paralelo à abordagem contratualista, que recebe grande atenção tanto no debate internacional quanto no nacional, passaram a desenvolver outra, mais participativa. Estas abordagens, bastante diferenciadas tanto na retórica, quanto em várias das suas práticas, têm, no entanto, se contaminado permanentemente como mostra a experiência de Mogi das 
Cruzes onde a OSS Cejam estabeleceu dinâmicas participativas na gestão das Unidades de Saúde da Família que gerenciam.

Por sua vez, a terceira hipótese do estudo sugere que a adoção de convênios de serviços e contratos de gestão contribuiu para aumentar a oferta de serviços básicos oferecidos pelo SUS.

Os resultados apresentados na seção Avaliando os impactos de adotar a estratégia de contratação indireta sugerem que esta hipótese deve ser mantida. Esses resultados mostram que, quando controladas as condições iniciais em diferentes municípios, houve um aumento de aproximadamente uma consulta básica por usuário SUS ao ano entre aqueles que adotaram a contratação indireta.

Ao discutirmos esses resultados com gestores públicos de saúde, dois mecanismos foram apontados para explicá-los. Em primeiro lugar, a adoção de contratos indiretos permite maior flexibilidade na contratação de pessoal, o que facilita a contratação de novos profissionais, seja quando unidades de saúde estão sendo abertas ou ampliadas, seja quando o rendimento dos profissionais não é satisfatório, seja, ainda, quando há alta rotatividade desses profissionais. Essa agilidade contribui para garantir a presença de profissionais nas unidades de saúde e, assim, ampliar a oferta de serviços prestados.

Em segundo lugar, os fornecedores de saúde ligados a contratos indiretos têm mais incentivos para registrar o atendimento de maneira precisa já que o contrato prevê alcançar objetivos predeterminados e os pagamentos não só ficam na dependência destas metas serem alcançadas, como há controle por parte de diferentes instâncias - Tribunal de Contas do Estado, Ministério Público e Controladoria do Município sobre a prestação das contas relativas a esses contratos. Nesse cenário torna-se difícil precisar quanto do aumento registrado no número de consultas básicas reflete um aumento real no número de consultas básicas e quanto diz respeito a um sistema de registro mais preciso. De qualquer forma, há nesse processo um ganho que foi destacado pelos gestores: a formalização do contrato que se estabelece entre o gestor municipal e o prestador de serviços e que resulta em um monitoramento mais cuidadoso de gastos e resultados.

Finalmente, a quarta hipótese do estudo sugere que a contratação de OSS na atenção básica pode levar a resultados na saúde da população 
menos favoráveis que aqueles alcançados por serviços que não utilizam este tipo de contratação.

Os resultados apresentados na seção Avaliando os impactos de adotar a estratégia de contratação indireta sugerem que esta hipótese deve ser descartada. Afinal, se não podemos afirmar que a contratação indireta contribuiu para a melhoria nas condições de saúde, podemos, no entanto, afirmar que não houve piora. Os resultados sugerem que a contratação indireta contribui para a redução da internação por causas sensíveis à atenção básica e sugerem melhoras relativas à mortalidade infantil e à internação por infecção respiratória aguda, embora em relação a esses dois últimos não possamos descartar que as estimativas por parâmetro sejam zero.

Na próxima seção são tecidas considerações no sentido de articular os achados apresentados até aqui.

\section{CONCLUSÃO}

O artigo apresenta um estudo sobre a contratação indireta, um fenômeno que vem ganhando espaço na administração pública brasileira, enfocando a área da atenção básica à saúde. Em 2012, 223 dos 645 municípios no estado de São Paulo recorriam à contratação indireta, o que por si só aponta para a importância crescente tanto dos convênios, quanto dos contratos de gestão na administração da atenção básica. Este estudo combinou abordagens qualitativa e quantitativa com o objetivo de investigar tanto as dinâmicas políticas e organizacionais que têm sustentado esse avanço, quanto seus impactos sobre a oferta de serviços e a saúde da população.

Nossos resultados situam a experiência brasileira na área da saúde em um terreno bastante diverso daquele que vem sendo descrito seja nos estudos empíricos que têm tratado da contratação indireta, seja na literatura mais disseminada na área de administração pública. Aqui não se tem contratado o setor privado stricto sensu, nem, tampouco, se adotou uma política sistemática de pagamento por resultado. O que ocorreu foi a contratação de entidades sem fins lucrativos para atuarem no interior do setor público. O setor público estabelece convênios com OSSs para fornecerem profissionais de saúde que prestam serviços em unidades públicas, como ocorre nos casos de São Bernardo do Campo e Embu, ou celebra contratos de gestão para gerirem essas unidades, como no caso de Mogi das Cruzes. 
Entrevistas com os gestores municipais indicaram que a adoção deste instrumento esteve associada aos limites à contratação de servidores públicos impostos pela Lei de Responsabilidade Fiscal. Nossos resultados mostram que os municípios responderam de forma relativamente homogênea à Lei de Responsabilidade Fiscal: adotaram os convênios, independentemente de contarem com as capacidades organizacionais consideradas necessárias para o seu sucesso. Políticos e gestores têm, no entanto, investido no aprimoramento dos sistemas municipais de atenção básica e, como consequência, no desenvolvimento dessas capacidades. Nesse movimento também buscaram moldar a gestão desses sistemas a práticas alinhadas ao discurso partidário. No caso do PT e partidos da coligação, isso significou investir em uma gestão mais participativa, enquanto o PSDB e seus coligados investiram em uma gestão mais contratualista. Essas experiências mostram que, para além do uso da contratação indireta no registro de uma abordagem contratualista, tal como proposto pela Nova Administração Pública, há um outro registro que segue uma abordagem mais participativa sendo praticado nos municípios. Entender melhor esses movimentos e sua filiação a diferentes tradições de pensar o desenvolvimento e as possibilidades de aprimoramento da gestão pública representa uma contribuição importante e não antecipada desta pesquisa.

Neste estudo também se analisou o impacto da adoção de convênios e contratos de gestão na atenção básica oferecida pelo SUS no estado de São Paulo. O balanço que os gestores entrevistados fazem sobre este tipo de contratação destaca tanto a sua contribuição para flexibilizar a gestão dos recursos humanos, quanto para o aprimoramento da gestão, seja por envolver algum grau de planejamento para o estabelecimento dos contratos, e de avaliação quanto ao cumprimento das metas acordadas, seja, ainda, pela necessidade de se prestarem contas sobre essas parcerias. Aponta, ainda, que a maior facilidade de contratação de profissionais teria contribuído para garantir a ampliação da rede de serviços nas periferias. Os resultados do estudo quantitativo mostraram efeitos significativos no número de consultas básicas e apontam para redução nas taxas de internação por causas sensíveis à atenção básica. Cabe, no entanto, ressaltar a dificuldade, indicada na seção Avaliando os impactos de adotar a estratégia de contratação indireta, de precisar quanto do aumento registrado no número de consultas básicas reflete um aumento real no número de consultas básicas e quanto diz respeito a um sistema de registro mais preciso. No seu conjunto, es- 
ses resultados apontam para evidências preliminares, embora não conclusivas, de que o recurso a contratos com entidades privadas não lucrativas, que desempenham funções de prestação e gestão de serviços no interior do setor público, pode contribuir para um melhor desempenho do sistema municipal de $\mathrm{AB}$.

Ao longo do estudo cinco dimensões relevantes foram identificadas na análise do sistema municipal de atenção básica: os constrangimentos legais, a gestão político-partidária, as capacidades organizacionais, o uso de contratos e a participação das OSSs. Que os constrangimentos legais importam ficou claro ao analisarmos o papel desempenhado pela Lei de Responsabilidade Fiscal no processo de adoção da contratação indireta, já a importância da gestão político-partidária pôde ser reconhecida nos dois modelos descritos, um mais participativo e outro mais contratualista. A identificação dessas dimensões representou um achado importante da pesquisa que não havia sido antecipado a partir da discussão da literatura. Em relação às demais dimensões deve ser enfatizado que este estudo aponta para a contribuição combinada dos contratos, do envolvimento das OSSs e do aprimoramento das capacidades organizacionais à gestão dos sistemas municipais de atenção básica. Desta perspectiva, caberá a estudos futuros identificar com maior rigor a contribuição específica de cada uma dessas dimensões aos resultados descritos neste artigo.

(Recebido para publicação em maio de 2015)

(Reapresentado em abril de 2016)

(Aprovado para publicação em junho de 2016) 


\section{As Organizações Sociais de Saúde e o Desempenho do SUS}

\section{NOTAS}

1. A Nova Administração Pública é uma linha de pensamento originária da junção dos princípios do gerencialismo com noções do campo teórico da microeconomia (Domberger e Jensen, 1997).

2. Essas dificuldades decorrem da rigidez da estrutura normativa da Administração Pública, que conta com um regime único de pessoal e de compras e contratações, além de formas de gerenciamento iguais para todo seu conjunto de órgãos e entidades, independentemente das competências que cada um exerce.

3. A lista dos tipos de prestadores utilizada pelo Sistema de Informações Ambulatoriais do SUS inclui: administração direta da saúde (órgãos do Ministério da Saúde e Secretarias Estaduais e Municipais de Saúde); administração indireta (autarquias, fundação pública, empresa pública, organização social); empresa privada; fundação privada; cooperativa, serviço social autônomo; entidade beneficente sem fins lucrativos; economia mista e sindicato.

4. No estado de São Paulo vivem 40 milhões de habitantes, que representam $20 \%$ da população total do Brasil e funciona o maior sistema de saúde pública do país.

5. No Estado, em $2008,15,2 \%$ dos gastos municipais com atenção básica foram comprometidos em contratações indiretas, tendo esse montante passado em 2012 para $34,5 \%$ (SIOPS, 2012).

6. O convênio está disciplinado no art. 116 da Lei Federal no 8.666, de 1993 (Lei de Licitações e Contratos), que estabelece procedimentos e exigências inclusive a obrigação da conveniada em prestar contas tanto ao ente repassador, quanto ao Tribunal de Contas (Di Pietro, 2000).

7. Por exemplo, no Paquistão, um programa que contratou uma ONG para levar serviços de saúde a áreas rurais obteve um aumento de quase quatro vezes no número de consultas ambulatoriais. Em Bangladesh, as áreas rurais que receberam serviços contratados de uma ONG reduziram em 18\% os índices de desnutrição, enquanto as áreas-controle apresentaram redução de $13 \%$.

8. Nessa categoria incluímos: vínculo empregatício celetista contrato por OSCIP, ONG ou por entidade filantrópica; autônomo intermediado por Organização Social, OSCIP, ONG, entidade filantrópica ou sem fins lucrativos e cooperativa.

9. O cálculo da população SUS foi feito a partir de uma aproximação, a população que conta com planos de saúde privados foi subtraída da população total.

10. Os indicadores selecionados foram: número de consultas médicas na atenção básica por usuário SUS; proporção de nascidos vivos que realizaram sete ou mais consultas de pré-natal; proporção de internações por causas sensíveis à atenção básica; taxa de mortalidade infantil, e gasto municipal por usuário SUS/ano na atenção básica. Esses indicadores foram calculados a partir de dados fornecidos pelas secretarias municipais de saúde e pelo DATASUS.

11. Disponível em: http://bit.ly/1SOmOdY.

12. Investigamos diversas maneiras de medir a contratação indireta. Em particular, comparamos medidas utilizando três fontes de dados: a) o número de profissionais de saúde na atenção básica contratados através de convênios ou contratos de gestão (Cadastro Nacional de Estabelecimentos de Saúde-CNES); b) um estudo qualitativo realizado em quatro municípios do estado de São Paulo (Coelho et al., 2014); e c) o 
gasto municipal com instituições ou organizações sem fins lucrativos em atividades relacionadas à atenção básica (Tribunal de Contas do Estado - TCE). Para 2012 há uma correlação significativa entre o número de funcionários em contratos externos e o gasto municipal com atividades relacionadas ao atendimento básico de saúde fornecido por instituições privadas ou organizações sem fins lucrativos.

13. Seguindo nossa definição de município tratado, aquele onde mais de $10 \%$ dos profissionais de saúde da atenção básica estavam em contratos externos em 2011, temos que em 2012 16\% dos municípios no estado de São Paulo usavam este tipo de contrato. Ver Tabela 3 do Anexo 1 (http:/ / bit.ly/1SOmOdY).

14. Na Tabela 1 do Anexo 1 on-line, são apresentados os resultados de avaliações feitas utilizando-se porcentagens tanto acima, quanto abaixo de $10 \%$ para o número de profissionais em contratos externos.

15. Ver testes de robustez no Anexo 3 (http:/ / bit.ly/1SOmOdY). Estes resultados também podem ser obtidos com as autoras.

16. Os gráficos mostrando essas tendências são apresentados no Anexo 4 (http://bit.ly/1SOmOdY).

17. O fato de municípios com uma porcentagem maior de pretos e pardos e de usuários do SUS terem menor probabilidade de introduzir uma estratégia de contratação indica que há uma seleção não aleatória de grupo de tratamento.

18. A mortalidade masculina foi deixada de fora da regressão devido à alta correlação com mortalidade feminina.

19. Em 2007 o PFL se reorganizou tendo mudado seu nome para Democratas (DEM).

20. Parte importante do programa que o Brasil consolidou ao longo dos anos para lidar com os desafios da atenção básica está expresso na Estratégia da Saúde da Família (ESF) que orienta os serviços locais a se organizarem a partir das Unidades Básicas de Saúde (UBSs), as quais contam com Equipes de Saúde da Família, compostas por médicos generalistas, enfermeiros e agentes comunitários que devem implementar os programas prioritários definidos pelo Ministério.

21. Para tornar esse quadro ainda mais crítico, cabe comentar que, entre 2008 e 2012, houve aumento da mortalidade infantil em dois dos quatro municípios pesquisados.

22. Esses programas são: eliminação da desnutrição infantil e hanseníase; controle da hipertensão, tuberculose e diabetes mellitus; promoção e cuidado com a saúde da criança, saúde da mulher, saúde do idoso e saúde bucal.

23. No teste apresentado na Tabela 1 do Anexo 3, Modelo 2, esse valor é de 1,3 consulta por usuário/SUS/ano.

24. O desvio padrão para a taxa de internação por causas evitáveis é relativamente baixo - o que sugere que o parâmetro apareceria como significativo a $15 \%$. Como o número de observações é baixo, podemos supor que encontraríamos erros-padrão mais baixos para um número maior de observações. No Anexo 3 (http:/ / bit.ly/1SOmOdY), pode-se observar que, em vários dos testes de robustez, a variável "taxa de internação por causas evitáveis" aparece como significativa (Tabelas 1, 2 e 3).

25. http://bit.ly/1SOmOdY

26. Posteriormente incluímos o Índice Firjan de Gestão Fiscal (IFGF) como uma variável de controle. O Índice foi tomado como uma proxy da capacidade fiscal e organizacional dos municípios. A inclusão desse índice levou a mudanças mínimas nos parâmetros estimados para a contratação indireta. 


\section{As Organizações Sociais de Saúde e o Desempenho do SUS}

\section{REFERÊNCIAS BIBLIOGRÁFICAS}

ANGRIST, Joshua D.; PISCHKE, Jorn-Steffen. (2009), Mostly Harmless Econometrics. Princeton/Oxford, Princeton University Press.

BARBOSA, Nelson B.; ELIAS, Paulo E. M. (2010), “As Organizações Sociais de Saúde como Forma de Gestão Público/Privado". Ciência \& Saúde Coletiva, vol. 15, no 5, pp. 2483-2495.

BARBOSA, Pedro R. (1996), “Gestão de Hospitais Públicos: Maior Autonomia Gerencial, Melhor Performance Organizacional com Apoio em Contratos de Gestão". Revista do Serviço Público, vol. 47, no 2, pp. 67-97.

BARRADAS, Luiz R. B.; MENDES, José D. (2006), Organizações Sociais de Saúde: A Experiência Exitosa de Gestão Pública do Estado de São Paulo. São Paulo, Secretaria do Estado de Saúde.

BASU, Sanjay et al. (2012), “Comparative Performance of Private and Public Health Care Systems in Low and Middle-Income Countries: A Systematic Review". PLOS Medicine, vol. 9 , no 6 .

BERENDES, Sima et al. (2011), "Quality of Private and Public Ambulatory Health Care in Low and Middle Income Countries: Systematic Review of Comparative Studies". PLOS Medicine vol. 8, № 4 .

CALDEIRA, Antonio P. et al. (2005), "Trends in Avoidable Causes of Infant Mortality in Belo Horizonte, Brazil, 1984 to 1998". Revista de Saúde Pública, vol. 39, no1, pp. 67-74.

CHAMBERS, Robert. (2010), "Paradigms, Poverty and Adaptive Pluralism". IDS Working Paper, no 344, Institute of Development Studies.

COELHO, Vera S.;SZABZON, Felipe; DIAS, Marcelo. (2014), “Política Municipal e Acesso a Serviços de Saúde". Novos Estudos Cebrap, no 100, pp. 139-161.

COELHO, Vera S. et al. (2014), Tackling Inequity in Health Provision: An Assessment of the Impact of Contracting Non-governmental Organizations. Trabalho apresentado no 23을 Congresso Internacional da IPSA. Montreal, 20-24 de julho.

DAB (Departamento de Assistência Básica). (2002), Avaliação da Implementação do Programa de Saúde da Família em Dez Grandes Centros Urbanos. Brasília, Editora Ministério da Saúde.

DI PIETRO, Maria S. Z. (2000), Direito Administrativo. 12a ed. São Paulo, Atlas.

DIJKGRAAF, Elbert; GRADUS, Raymond H. J. M.; MELEMBERG, Bertrand. (2003), "Contracting out Refuse Collection". Empirical Economics Review, vol. 23, pp. 553-570.

DOMBERGER, Simon; JENSEN, Paul. (1997), “Contracting out by the Public Sector: Theory, Evidence and Prospects". Oxford Review of Economic Policy, vol. 4, pp. 67-78.

DOWBOR, Monika; HOUTZAGER, Peter. (2014), “The Role of Professionals in Policy Reform: Cases from the City Level, São Paulo". Latin American Politics and Society, vol. 56, no 3, pp. 141-162.

ENGLAND, Roger. (2004), Experience of Contracting with the Private Sector: A Selective Review. London, DFID Health Systems Resource Centre. 


\section{Vera Schattan P. Coelho e Jane Greve}

EYBEN, Roselyn. (2010), “Hiding Relations: The Irony of 'Effective Aid'”. European Journal of Development Research, vol. 22, pp. 382-397.

GRAEF, Aldino; SALGADO, Valéria. (2009), “As Relações com as Entidades Privadas sem Fins Lucrativos no Brasil", in Anais do 14o Congresso Internacional do Centro Latinoamericano de Administración para el Desarrollo. Salvador, 27-30 de outubro, pp. 27-30.

IBAÑEZ, Nelson; VECINA NETO, Gonzalo. (2007), "Managment Models and Brazil's National Health System (SUS)". Ciência e Saúde Coletiva, vol. 12, pp. 1831-1840.

IMBENS, Guido W.; WOOLDRIDGE, Jeffrey M. (2009), "Recent Developments in the Econometrics of Program Evaluation". Journal of Economic Literature, vol. 47, no 1, pp. $5-86$.

LaFORGIA, Gerard; COUTTOLENC, Bernard. (2008), Hospital Performance in Brazil. The Search for Excellence. Washington D.C., The World Bank.

LIU, Xingzhu; HOTCHKISS, David R.; BOSE, Sujata. (2008), "The Effectiveness of Contracting-out Primary Health Care Services in Developing Countries: A Review of the Evidence". Health Policy and Planning, vol. 23, no 1, pp. 1-13.

LOCKE, Edwin; LATHAM, Gary P. (2006), "New Directions in Goal-setting Theory". Current Directions in Psychological Science, vol. 15, no 5, pp. 265-268.

LOEVINSOHN, Benjamin; HARDING, April. (2004), "Contracting for the Delivery of Community Health Services: A Review of Global Experience". World Bank Discussion Paper; no 31506, Washington.

LÓPEZ-DE-SILANES, Florencio; SHLEIFER, Andrei; VISHNY, Robert W. (1997), “Privatization in the United States". Rand Journal of Economics, Santa Monica, vol. 28, no 3, pp. 447-471.

MACINKO, James et al. (2007), “Going to Scale with Community-based Primary Care: An Analysis of the Family Health Program and Infant Mortality in Brazil, 1999-2004". Social Science and Medicine, no 65, pp. 2070-2080.

MARE (Ministério da Administração Federal e da Reforma do Estado do Estado). (1997), "Organizações Sociais". Cadernos MARE de Reforma do Estado, vol. 2. Brasília.

MÉDICI, André. (2011), “Propostas para Melhorar a Cobertura, Eficiência e a Qualidade no Setor Saúde", in E. L. Bacha; S. Schwartzman (orgs.), Brasil: A Nova Agenda Social. Rio de Janeiro, LTC, pp. 23-93.

MENDES RIBEIRO, José; COSTA, Nilson do Rosário. (2005), “Mecanismos de Governança e Modelos Alternativos de Gestão Hospitalar no Brasil". Relatório de Consultoria para o Banco Mundial. Rio de Janeiro, Fiocruz/ENSP.

MILLS, Anne. (1998), "To Contract or Not Contract: Issues for Low and Middle Income Countries". Health Policy and Planning, vol. 13, no 1, pp. 31-40.

OLIVEIRA, Ana C. O. (2016), Dinâmica Política e Política de Gestão: Partidos de Esquerda e a Adoção das Parcerias com Organizações Sociais no Brasil. Tese (Doutorado em Administração Pública). Escola de Administração de Empresas de São Paulo da Fundação Getulio Vargas, São Paulo.

PAHIM, Maria Luiza L. (2009), Organizações Sociais de Saúde do Estado de São Paulo: Inserção Privada no SUS e Gestão Financeira do Modelo pela Secretaria de Estado da 
Saúde. Tese (Doutorado em Saúde Coletiva). Faculdade de Medicina, Universidade de São Paulo, São Paulo. Disponível em http://www.teses.usp.br/teses/disponiveis/5/5137/tde-08122009-185716/pt-br.php. Acessada em julho de 2011.

PATTON, Michael. (2010), Developmental Evaluation Applying Complexity Concepts to Enhance Innovation and Use. New York, Guilford Press.

QUINHÕES, Trajano A. (2009), O Modelo de Governança das Organizações Sociais de Saúdee a Qualidade do Gasto Público Hospitalar Corrente. Brasília, Prêmio Tesouro Nacional Euclides.

SANO, Hironobu; ABRUCIO, Fernando L. (2008), "Promessas e Resultados da Nova Gestão Pública no Brasil: O Caso das Organizações Sociais de Saúde em São Paulo". Revista de Administração de Empresas, vol. 48, no 3, pp. 64-80.

SAVAS, Emanuel S. (1987), Privatization: The Key to Better Government. Chatham, NJ, Chatham House.

SIOPS (Sistema de Informações sobre Orçamentos Públicos em Saúde). (2012), Siops. datasus.gov.br

SHI, Leiyu. (2012), The Impact of Primary Care: A Focused Review. Baltimore, Johns Hopkins Bloomberg School of Public Health.

WALSH, Kieron. (1995), Public Services and Market Mechanisms. Competition, Contracting and the New Public Management. Basingstoke, Macmillan.

WITTER, Sophie et al. (2012), "Paying for Performance to Improve the Delivery of Health Interventions in Low - and Middle-Income Countries". The Cochrane Library, Issue 2.

WORLD BANK. (2006), “Enhancing Performance in Brazil's Health Sector: Lessons from Innovations in the State of São Paulo and Curitiba". Report $n$ o 35691-BR, Geneva. 


\section{RESUMO}

\section{As Organizações Sociais de Saúde e o Desempenho do SUS: Um Estudo sobre a Atenção Básica em São Paulo}

$\mathrm{O}$ artigo parte do debate sobre ganhos que podem advir do uso de contratos e do envolvimento de organizações não estatais na prestação de serviços públicos enfocando a experiência de contratação de organizações sociais de saúde na prestação de serviços públicos nesta área. Discute-se o que leva políticos e gestores públicos a contratarem essas organizações, como são geridos os contratos celebrados, avaliando-se, ainda, seu impacto na atenção à saúde oferecida pelo Sistema Único de Saúde (SUS). Para tanto partiu-se de duas abordagens, uma qualitativa e outra quantitativa, tendo-se analisado o envolvimento destas organizações na prestação de serviços de atenção básica no estado de São Paulo. O estudo qualitativo cobriu 4 municípios de porte médio, enquanto o estudo quantitativo avaliou o uso dos contratos nos 645 municípios do Estado. Os resultados mostram que: 1) Os municípios vêm recorrendo crescentemente aos contratos com organizações sociais de saúde; 2) Políticos e gestores filiados a partidos de diferentes matizes ideológicos têm aderido a esse tipo contratação; 3) Há indicações, preliminares e não conclusivas, que a adoção desses contratos tem contribuído para um aumento no número de consultas oferecidas aos usuários doSUS, bem como para a redução na internação por causas sensíveis à atenção básica.

Palavras-chave: Sistema Único de Saúde; Organizações Sociais de Saúde; convênios; contratos de gestão; análise de processo político; avaliação de impacto

\section{ABSTRACT \\ Social Health Organizations and the Performance of the SUS: A Study on Basic Healthcare in São Paulo}

The article begins with the debate on the advantages of the use of contracts and the involvement of non-governmental organizations in the provision of public services, focusing on the contracting of social health organizations for the provision of public services in this area. We discuss what leads politicians and public administrators to contract such organizations and how the signed contracts are managed, also assessing the impact on the healthcare offered by the Unified Health System (SUS). The article therefore begins with two approaches - one qualitative and the other quantitative - analyzing the involvement of the organizations in the provision of basic healthcare services in the state of São Paulo. The qualitative study encompassed 4 medium-sized municipalities, while the quantitative study assessed the use of contracts across the state's 645 municipalities. The results demonstrate that: 1) the municipalities have increasingly come to rely on contracts with social health organizations; 2) Politicians and administrators affiliated to parties with different ideological nuances have adhered to this type of contracts; 3 ) there are preliminary yet inconclusive indications that the adoption of these contracts has contributed to an increase in the number of medical consultations offered to SUS users, as well as a decrease in the hospitalization of patients that may be treated by basic healthcare.

Key words: Unified Health System; social health organizations; agreements; management contracts; political process analysis; impact assessment 


\section{RÉSUMÉ}

\section{Les Institutions à Vocation Médico-sociale et les Performances du SUS:} Une Étude sur la Médecine Générale à São Paulo

Cet article s'appuie sur le débat relatif aux bénéfices pouvant procéder de l'usage de contrats de partenariat et de l'implication d'organisations indépendantes de l'État dans la prestation de services publics. On s'intéressera à cet effet aux expériences de partenariat avec des institutions à vocation médico-sociale pour la prestation de services publics. On débattra ici de ce qui amène les politiques et les gestionnaires publics à faire appel à ces organisations et de la manière dont sont gérés les contrats signés, et on évaluera enfin l'impact de ceux-ci sur les services de médecine générale offerts par le Système unique de santé-SUS. Nous avons à cette fin fait usage de deux approches, une qualitative et une quantitative, pour analyser l'implication de ces organisations dans la prestation de services de santé dans l'État de São Paulo. L'étude qualitative s'est intéressée à quatre communes de taille moyenne, tandis que le travail quantitatif a permis de répertorier l'usage de ces contrats dans les 645 communes de l'État. Les résultats montrent que: 1) les communes font de plus en plus appel à ces contrats; 2) des politiques et gestionnaires affiliés à des partis d'orientation idéologique différente ont adhéré à ce type de convention; 3) Il existe de forts indices de ce que l'adoption de ces contrats ait contribuer à l'augmentation du nombre de consultations offertes aux usagers du SUS, ainsi qu'à la réduction du nombre d'hospitalisations pour des raisons relevant de la médecine générale.

Mots-clés: Système unique de santé; institutions médico-sociales; conventions; contrats de gestion; analyse des processus politiques; évaluation d'impact

\section{RESUMEN}

\section{Las Organizaciones Sociales Sanitarias y el Desempeño del SUS: Un Estudio de la Atención Básica en São Paulo}

El artículo se basa en el debate sobre las ganancias que puede generar el uso de contratos y del involucramiento de organizaciones no estatales en la prestación de servicios públicos, enfocando en la experiencia de contratación de organizaciones sociales sanitarias en la prestación de servicios públicos en esta área. Se analiza lo que lleva políticos y gestores públicos a contratar esas organizaciones, cómo son gestionados los contratos celebrados, evaluando también su impacto en la atención sanitaria ofrecida por el Sistema Único de Salud (SUS). Para ello, se consideraron dos abordajes, uno cualitativo y otro cuantitativo, habiéndose analizado el involucramiento de estas organizaciones en la prestación de servicios de atención básica en el estado de San Pablo. El estudio cualitativo cubrió 4 municipios de tamaño mediano, cuando el estudio cuantitativo evaluó el uso de los contratos en los 645 municipios del Estado. Los resultados muestran que: 1) Los municipios van apelando cada vez más a los contratos con organizaciones sociales sanitarias; 2) Políticos y gestores afiliados a partidos de diferentes matices ideológicos adhirieron a este tipo de contratación; 3) Hay indicaciones, preliminares y no conclusivas, que la adopción de estos contratos ha contribuido a un aumento en el número de consultas ofrecidas a los usuarios del SUS, así como a la reducción de la internación por causas sensibles a la atención básica.

Palabras clave: Sistema Único de Salud; Organizaciones Sociales de Salud; convenios; contratos de gestión; análisis de proceso político; evaluación de impacto 